\title{
A COMPARATIVE STUDY ON THE PERFORMANCE OF THREE COLOR SCHEMES IN LANDSCAPE PREFERENCE TESTS
}

\author{
Tao $\mathrm{LUO}^{1,2}$, Min XU1, Zhifang $\mathrm{WANG}^{3^{*}}$, Zhaowu YU \\ ${ }^{1}$ Institute of Urban Environment, Chinese Academy of Sciences, Xiamen, China \\ ${ }^{2}$ School of Architecture, Fuzhou University, Fuzhou, China \\ ${ }^{3}$ College of Architecture and Landscape Architecture, Peking University, Beijing, China \\ ${ }^{4}$ Department of Geosciences and Natural Resource Management, Faculty of Science, \\ University of Copenhagen, Copenhagen, Denmark
}

Received 28 August 2018; accepted 10 January 2019

\begin{abstract}
The photo color is recognised as one of the most significant but not fully understood factors influencing the results of landscape preference research. In this context, this paper compares the performances of three photo color schemes (original, rendered and white-black color schemes) frequently used in landscape preference tests to figure out which is the more suitable alternative to an original color photo. Statistics analysis results demonstrated that: 1) In general, the photo color schemes particularly the white-black scheme will significantly affect the results of landscape preference test. Compared with white-black, color in any other forms can increase the degree of preference for a given landscape. 2) The photo color scheme plays a decisive role in respondent's judgment on some landscape attributes. Original color, White-black color and Rendered color schemes are better suited in landscape preference tests that highlight the effect of color, characteristic and naturalness respectively. 3) When the Rendered color scheme is used as an alternative to the Original color scheme, it has a much better performance than the White-black Color Scheme and is therefore recommended as the prior alternative color scheme to the Original color scheme under most scenarios in landscape preference research. Based on these results, it is suggested that color should be more carefully treated according to its different performance in landscape cognition research.
\end{abstract}

Keywords: public test, landscape aesthetics, photo visualization, rendered photos, landscape management.

\section{Introduction}

Researchers have been seeking to operationalize human aesthetic values through systematic studies of landscape preferences and other aspects of landscape experience. In the past 40 years, environmental psychologists also have sought to understand human beings' landscape preference by associating respondents' evaluations of photos that describe real landscapes with the presence of objects, structures, spaces, colors or concepts represented within the photos. The researches of landscape preference are one of the oldest theses in psychology, having been pioneered by Fechner (1876), one of the founders of modern scientific psychology. Since the 1960s, user-dependent approaches gained popularity in landscape perception analysis to compensate for the inadequate levels of precision, reliability and validity of expert-based landscape assessments (Hayden, Cadenasso, Haver, \& Oki, 2015; Natori \& Chenoweth, 2008; Soini, Vaarala, \& Pouta, 2012). Thereafter, the visualization of landscapes was becoming a central part of landscape perception and preference research $(\mathrm{Hu}$, Ge, \& Hou, 2014; Polat \& Akay, 2015), where photographs were the most frequently used tools in landscape appraisal and development control matters (Lindquist, Lange, \& Kang, 2016). Landscape photos were proved to be a suitable and reliable media for landscape visualization, though they might filter reality to some extent. As image information, compared to other forms of information, such as text information, and audio information (Chesnokova \& Purves, 2018), photos are more controllable for researchers and more understandable for their respondents (Orenstein, Zimroni, \& Eizenberg, 2015).

Landscape studies have exploited photographic materials particularly well (Lee \& Son, 2017). Integrating photographs with spatial data has benefited tests of detecting the relationship between preferences and landscape elements (Lange, Hehl-Lange, \& Brewer, 2008; Svobodova,

*Corresponding author. E-mail: zhifangw@pku.edu.cn 
Sklenicka, Molnarova, \& Vojar, 2014; Palmer, Schloss, \& Sammartino, 2013; Tieskens, Van Zanten, Schulp, \& Verburg, 2018). Photographs within qualitative research activities can stimulate types of information not necessarily obtainable through verbal exchanges (López-Martínez, 2017). More recently, the digital editing of photographs (photo-montage, image capture technique or true color abstracting) has also been used (García, Hernández, \& Ayuga, 2003). As previous research showed, selected photos which were modified with the Photoshop CS6 editing software were used to investigate how environmental characteristics influence the restorative qualities in hospital staff break areas (Nejati, Rodiek, \& Shepley, 2016).

As the most commonly used test medium for landscape preference, the discussion of the photo color is inevitable. People's preference for color is a historical topic. Theoretical and empirical researches about the preference of color have been tested by a variety of experiments. Despite the many differences of individuals, Schloss and Palmer (2017), Gong, Wang, Hai, and Shao, (2017) test illustrated that group color preferences showed systematic and reliable patterns. Schloss and Palmer et al. (2013) assessed the aesthetics of color and explained the distinction between preference and harmony. And the research predicted that colors do affect people's landscape preference judgment. As far as color is concerned, original color and black-andwhite color have been becoming the most commonly used schemes in landscape preference studies since the 1960s. It has been shown that the original color has the advantage of reflecting environmental information to the largest degree. However, to ensure the consistency of color reproduction of a given scene, high quality is required in the acquisition and post-processing of original color photos, which usually leads to an increase in financial and technical research costs. Although black-and-white color photos are cheap and are simple to deal with, their usage leads to a great loss of useful environmental information. Beyond that, some rendered photos have also been used in landscape tests (Deussen, 2003). However, this color scheme is not widely applied because the treatment process of photos is mainly based on P. S. skills. Despite the common acknowledgment that color plays an important role in landscape preference research (Nardecchia et al., 2015), the usage of photo color scheme is often subjective. There is no qualitative description about how color scheme influences a respondent's preference judgment. For instance, to study the importance of water in landscape preference, black-and-white photos were employed by Yamashita (2002), while photos with their original color scheme were used by Mahdieh and Mustafa Kamal (2014), and Surová and Pinto-Correia (2016) used black-and-white photos to investigate how environmental characteristics influence the restorative qualities in hospital staff break areas, et al.

These problems have become particularly prominent when studying landscape dynamics and preferences and comparing historical black-and-white photographs with modern photographs with rich colors. How to unify the above two color schemes into a common test model becomes an important issue in the rationality of landscape preference test design. However, the top priority that using the color rendition technology to deal with black-andwhite historical photos is almost impossible for its high costs. Therefore, researchers usually turn to choose from two possible alternatives: one way is to change the color of modern photos into black-and-white ones at the cost of losing a lot of landscape information; another way is to render both black-and-white historical photos and original color photos into a unified color scheme using a standard processing method. Thus, the question is: what kind of scheme(s) (black-and-white and/or rendered) of the landscape preference test will produce results that closer to that of original color photos?

In this paper, by identifying both consensus and differences between Rendered, White-black and Original color schemes, (abbreviated as R-Scheme, WB-Scheme and OScheme, respectively), two scientific problems will be addressed under different research questions and scenes: 1) how much do different photo color schemes influence the results of the landscape preference test and what are the influencing mechanisms? 2) How can we avoid the unexpected influences of photo color and rationally choose a suitable color scheme in the landscape preference test?

\section{Methods and research design}

\subsection{Photo acquisition and processing}

Six representative photos were selected from a photo pool which contained 17 panoramic photos taken in 13 areas in Fujian province, China, and used in the preference test. All photos were divided into natural elements, including hills, greensward, trees, water surfaces, sky, and manmade elements such as buildings, impervious surfaces and traditional buildings. Excluding the sky, the area proportion of each element in each photo was calculated. The naturalness of each photo was the summed proportion of the natural elements. Finally, six photos were selected according to the proportion gradient of naturalness covering the range from $28 \%$ to $72 \%$ (Figure 1 ). Then, the photos were translated into the other 2 color schemes, WBScheme and R-Scheme, using photo editor software. The RGB (tricolor) color codes of the landscape elements of Rendered Color Scheme were shown in Table 1.

Table 1. RGB color codes of the landscape elements of Rendered Color Scheme

\begin{tabular}{|l|c|c|c|}
\hline Parameters for RGB & R (RED) & G (GREEN) & B (BLUE) \\
\hline Sky & 115 & 223 & 255 \\
\hline Hill body & 76 & 230 & 0 \\
\hline Greensward & 85 & 255 & 0 \\
\hline Trees & 56 & 168 & 0 \\
\hline Water surface & 0 & 112 & 255 \\
\hline Buildings & 255 & 85 & 0 \\
\hline Impervious surface & 255 & 211 & 127 \\
\hline Traditional buildings & 255 & 0 & 0 \\
\hline
\end{tabular}




\subsection{Questionnaire design}

All research questions were rated on a modified Likert 5-point scale (Zhang, Chen, Sun, \& Bao, 2013). To clarify the intent of each scale mark, gradations of assessment were labelled with the adverbs "strongly" and "slightly", with "neutral" describing the midpoint (Verbrugge \& van den Born, 2018) (Details can be seen in Table 2) (see details @:http://www.sojump.com/jq/4345980.aspx).
Research question number 1 (Q1) was about aesthetic evaluation, and Q2 was about liveability evaluation of the landscape. Both two indicators were comprehensive evaluation of landscape. Q3 and Q4 were mainly used to test the respondents' judgment of a scene's naturalness, from objective to subjective. For Q3 was an objective description of the landscape attributes-naturalness, and Q4 was a personal evaluation of naturalness. Q5, Q6 were playing
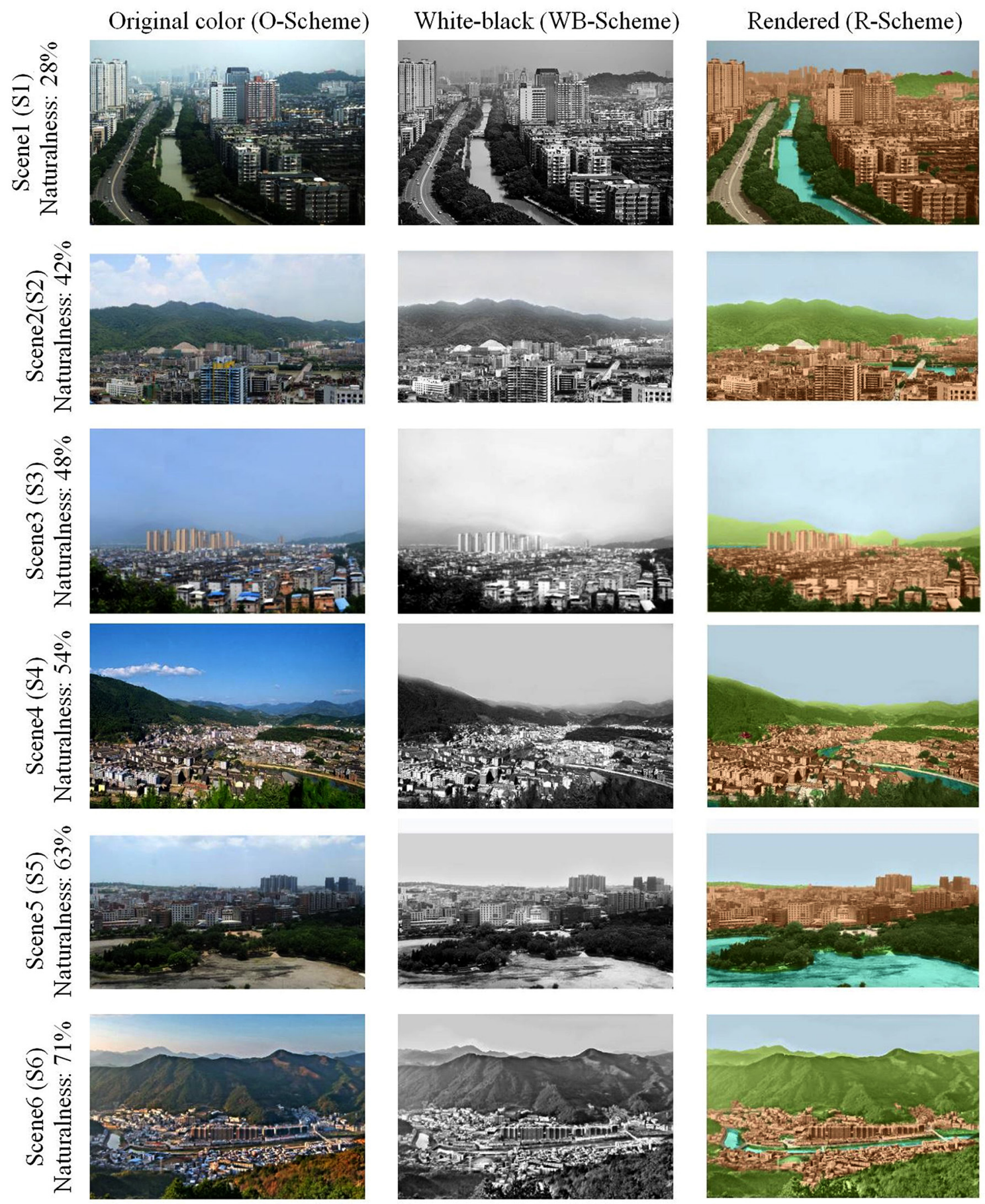

Figure 1. Test photos with different proportions of naturalness. S1-S6 are arranged in a sequence that the proportion of naturalness increases orderly 
the same role as Q4. Q5 was designed to evaluate landscape characteristic; Q6 was set to evaluate respondents' color preference. Among these, the answers to Q1 and Q2 displayed respondents' landscape preference, while Q4, Q5, and Q6 were the main factors that influence their preference judgement of landscape. Naturalness (Wang, Zhao, \& Liu, 2016; Wang \& Zhao, 2017), characteristics (C. Acar, B. C. Kurdoglu, O. Kurdoglu, \& H. Acar, 2006; Atik, Isikli, \& Ortacesme, 2016) and color (Lengen, 2015) have been regarded as particularly powerful factors in preference judgment, and the significance of these factors had been demonstrated across several studies. Moreover, García et al. (2003), SowińskaSwierkosz (2016) had shown that all these factors had a certain relationship with color. At the end of the test, a QA was sent to directly inquire about the respondents' feedback. The logical relationships of the research questions are shown in Figure 2.

Table 2. Questionnaire design

\begin{tabular}{|c|c|c|}
\hline Questions (Q) & Options & Dimensions \\
\hline $\begin{array}{l}\text { Q1. Do you think } \\
\text { the urban landscape } \\
\text { reflected in the photo } \\
\text { beautiful? }\end{array}$ & $\begin{array}{l}1 \text { for strongly } \\
\text { ugly, } 5 \text { for } \\
\text { strongly } \\
\text { beautiful }\end{array}$ & $\begin{array}{l}\text { Aesthetic preference } \\
\text { of the designated } \\
\text { urban landscape }\end{array}$ \\
\hline $\begin{array}{l}\text { Q2. Are you willing to } \\
\text { live in the city reflected } \\
\text { in the photo? }\end{array}$ & $\begin{array}{l}1 \text { for strongly } \\
\text { unwilling, } 5 \\
\text { for strongly } \\
\text { willing }\end{array}$ & $\begin{array}{l}\text { Livability preference } \\
\text { of the designated } \\
\text { urban landscape }\end{array}$ \\
\hline $\begin{array}{l}\text { Q3. What is the } \\
\text { approximate } \\
\text { proportion of the } \\
\text { natural landscape } \\
\text { elements (Greensward, } \\
\text { trees, hill body, water } \\
\text { surface) to the whole } \\
\text { landscape in the photo? }\end{array}$ & $\begin{array}{l}1 \text { for }<20 \%, 2 \\
\text { for } 20-40 \%, 3 \\
\text { for } 40-60 \%, 4 \\
\text { for } 60-80 \%, 5 \\
\text { for }>80 \%\end{array}$ & $\begin{array}{l}\text { The cognitive } \\
\text { judgment on the } \\
\text { proportion of } \\
\text { natural landscape } \\
\text { elements in the } \\
\text { designated urban } \\
\text { landscape }\end{array}$ \\
\hline $\begin{array}{l}\text { Q4. How do you feel } \\
\text { about the naturalness } \\
\text { of the urban landscape } \\
\text { reflected in the photo? }\end{array}$ & $\begin{array}{l}1 \text { for strongly } \\
\text { artificial, } 5 \\
\text { for strongly } \\
\text { natural }\end{array}$ & $\begin{array}{l}\text { The cognitive } \\
\text { judgment on } \\
\text { naturalness of the } \\
\text { designated urban } \\
\text { landscape }\end{array}$ \\
\hline $\begin{array}{l}\text { Q5. How do you think } \\
\text { the characteristic of } \\
\text { the urban landscape } \\
\text { reflected in the photo? }\end{array}$ & $\begin{array}{l}1 \text { for } \\
\text { strongly no } \\
\text { characteristic, } \\
5 \text { for strongly } \\
\text { characteristic }\end{array}$ & $\begin{array}{l}\text { The cognitive } \\
\text { judgment on } \\
\text { landscape } \\
\text { characteristic of the } \\
\text { designated urban } \\
\text { landscape }\end{array}$ \\
\hline $\begin{array}{l}\text { Q6. Do you like the } \\
\text { color matching in the } \\
\text { photo? }\end{array}$ & $\begin{array}{l}1 \text { for strongly } \\
\text { dislike, } 5 \text { for } \\
\text { strongly like }\end{array}$ & $\begin{array}{l}\text { The preference of } \\
\text { color matching of } \\
\text { the designated urban } \\
\text { landscape }\end{array}$ \\
\hline $\begin{array}{l}\text { QA: Whether different } \\
\text { color schemes (original, } \\
\text { white-black, rendered) } \\
\text { have influenced your } \\
\text { judgment? }\end{array}$ & $\begin{array}{l}1 \text { for no } \\
\text { influence, } \\
3 \text { for } \\
\text { tremendous } \\
\text { influence }\end{array}$ & - \\
\hline
\end{tabular}

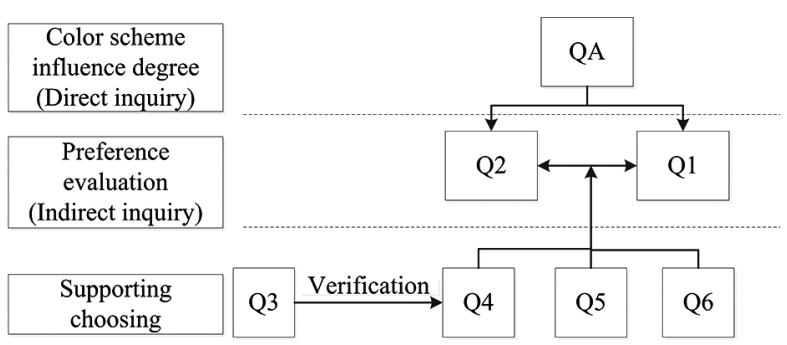

Figure 2. The logical framework of the research questions. Q1 and Q2 provide a general evaluation of the landscape, while Q4, Q5 and Q6 were set to explain the valuation of Q1 and Q2 from three dimensions of naturalness, characteristic and color matching, respectively

\subsection{Respondents and testing process}

The participants were all students from colleges and universities (for example, College of Architecture and Landscape architecture of Peking University; Institute of Urban Environment, Chinese Academy of Sciences; School of Architecture, Tianjin University; Minnan Normal University), with the same background (specialties of Urban Planning, Architecture and Landscape Architecture etc.) (Dupont, Antrop, \& Van Eetvelde, 2015). The ratio of male to female was 78:126. The web-link of the online questionnaire was sent to the respondents randomly. It was shown by Stamps (1990) that there was a significant correlation between on-site preference and determined photos. Photos used on the on-line test were chosen to demonstrate the validity of this assertion.

Photos from WB-Scheme S1 to S6, then R-Scheme and O-Scheme were shown to the respondents. After each photo, respondents were required to answer the aforementioned 6 questions. Participants responded by clicking the appropriate number on the scale $(1=$ strongly ugly, dislike, not at all, etc. 5 = strongly beautiful, like, very much, etc.). Lastly, the respondents were asked to answer QA at the end of the test.

After screening, there were a total of 204 valid responses to be analysed.

\subsection{Data processing and analysis}

The database was adjusted to adapt the need of ANOVA analysis under different questions and sceneries. So, the total sample size was set 6 times of 204 (for 6 different questions), and then 6 times of $204^{\star} 6$ (for 6 different scenes).

A mean value analysis was undertaken to give an overall view of the results. The correlation between the threecolor schemes were tested via a 2 -tailed correlation analysis. The differences were tested by analysis of two related samples using a non-parametric test. The influence degree of Q4, Q5 and Q6 on Q1 and Q2 were analysed by a partial correlation analysis. All statistical analysis was carried out using SPSS 19.0 (IBM Corp., Armonk, NY).

In order to define the alternative color schemes, the test hypothesis was set as follows: 1) if there exists 
significant difference on data distribution $(\mathrm{p}<0.050$, 2-tailed) between $\mathrm{O}$ - and R-Scheme, or O- and WBScheme, none of the alternative color schemes could take place of $\mathrm{O}$-Scheme; 2) if the difference between the $\mathrm{O}$ and R-Schemes, or O- and WB-Schemes is not significant, but the correlation between them is significant $(\mathrm{p}<0.050$, two-tailed), the O-Scheme could be replaced by $\mathrm{R}$ - or WB-Scheme correspondingly.

\section{Results}

\subsection{Total performance of color schemes}

Given that five of the questions (i.e. ordinal variables) were designed to quantify the participants' cognitive and preference evaluation of the photos, Q3 (a nominal variable) was designed to provide an estimation of the natural elements contained in a given photo, Q3 was not considered in the analysis of the effects of different color schemes on participants' preference. At the same time, the strong correlation between Q3 and Q4 ( $\mathrm{r}=0.730, \mathrm{p}<0.010)$ also supports the exclusion of Q3 in the comprehensive statistical analysis.

According to the whole data set, except for Q3 ( $\mathrm{n}=$ $204 \times 5 \times 6$ ), the mean value of the O-, R- and WB-Schemes were 3.06, 3.07 and 2.89, respectively. The R-Scheme obtained the largest average score, while the WB-Scheme got the smallest. The mean difference between $\mathrm{O}$ - and $\mathrm{R}$-Schemes was -0.010 , which meant that the R-Scheme could slightly raise a respondent's preference. As shown in Figure 3, there was no difference between $\mathrm{R}$ - and $\mathrm{O}$ Schemes, except for the score percentage at score $=3$. The mean difference between $\mathrm{O}$ - and WB-Schemes was +0.170 . The WB-Scheme could generally reduce a participant's preference by almost 5.6\%, except for the score percentage at score $=3$, The WB-Scheme had significant differences with the percentages of the other scores of the $\mathrm{O}$-Scheme. The percentage of the WB-Scheme was significantly larger than the $\mathrm{O}$-Scheme at score $=1$ and score $=$ 2 , but significantly smaller than that at scores $=4$ and score $=5$ (Figure 3 ).

A bivariate correlation analysis showed that the threecolor schemes were significantly correlated $(p<0.050$,

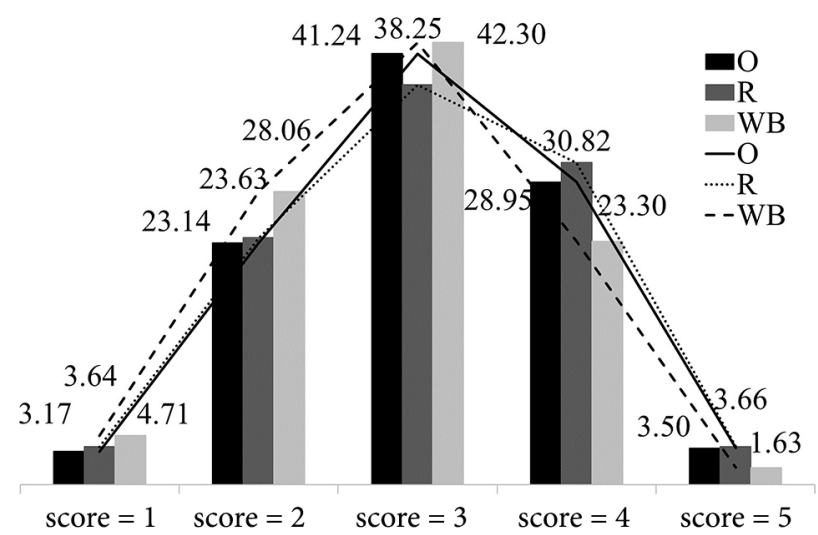

Figure 3. The overall score (percentage) proportion distribution under different color schemes $(n=204 \times 5 \times 6)$ two-tailed). The $\mathrm{N}$ Par-test showed that the difference significance between $\mathrm{O}$ - and R-Schemes was 0.460 ( $\mathrm{p}>$ 0.050 , two-tailed), while that of the $\mathrm{O}$ - and WB-Schemes was 0.000 ( $\mathrm{p}<0.050$, two-tailed) (Table 3 ). The O-Scheme could be replaced by the R-Scheme due to the insignificant difference ( $p>0.050$, two-tailed) between them according to the hypothesis; the O-Scheme could not replace the WB-Scheme, as the significant difference was less than 0.050. The final feedback from the participants in the questionnaire (QA) also confirmed the conclusion that most of the participants (98\%) believed that there exists an impact, of which $65 \%$ thought that color would strongly impact their landscape preference judgment.

Table 3. Mean difference and correlations of the 2 alternative schemes to original color scheme $(n=204 \times 5 \times 6)$

\begin{tabular}{|l|c|c|}
\hline & O-R & O-WB \\
\hline Mean diff. & -0.010 & 0.170 \\
\hline Corr. coef. & $0.444^{\star *}$ & $0.479^{\star \star}$ \\
\hline Diff. Sig. & 0.460 & 0.000 \\
\hline
\end{tabular}

Note: " $n$ " means the sample size; O means O-Scheme, and R is RScheme, WB is WB-Scheme; ${ }^{* *}$ means when the confidence level is 0.010 , the correlation or difference is significant (two-tailed).

\subsection{Performance of color schemes under different research questions}

All data were firstly grouped according to different questions. The mean differences between $\mathrm{O}$ - and R-Schemes, as well as O- and WB-Schemes, were calculated for each question, and a correlation and difference significance analysis were also carried out. The results were shown in Table 4 .

Table 4. The mean difference, the correlation, and the difference significance between $\mathrm{O}$ - and R-Schemes, as well as O- and WB-Schemes, for each question $(n=204 \times 6)$

\begin{tabular}{|l|l|c|c|c|c|}
\hline & \multicolumn{1}{|c|}{ Pairs } & $\begin{array}{c}\text { Mean } \\
\text { diff. }\end{array}$ & $\begin{array}{c}\text { Corr. } \\
\text { coef. }\end{array}$ & Diff. Sig. & $\begin{array}{c}\text { Alte. } \\
\text { Scheme }\end{array}$ \\
\hline \multirow{2}{*}{ Q1 } & O-R & -0.03 & $0.438^{\star *}$ & 0.283 & $\mathrm{R}$ \\
\cline { 2 - 6 } & O-WB & 0.103 & $0.496^{\star *}$ & 0.000 & $\times$ \\
\hline Q2 & O-R & -0.067 & $0.480^{\star *}$ & 0.009 & $\times$ \\
\hline $\begin{array}{l}\text { O-WB } \\
\text { 0.082 }\end{array}$ & & $0.501^{\star *}$ & 0.001 & $\times$ \\
\hline Q3 & O-R & -0.132 & $0.624^{\star *}$ & 0.000 & $\times$ \\
\cline { 2 - 6 } & O-WB & 0.141 & $0.617^{\star *}$ & 0.000 & $\times$ \\
\hline \multirow{2}{*}{ Q4 } & O-R & -0.077 & $0.522^{\star *}$ & 0.002 & $\times$ \\
\cline { 2 - 6 } & O-WB & 0.158 & $0.531^{\star *}$ & 0.000 & $\times$ \\
\hline \multirow{2}{*}{ Q5 } & O-R & -0.061 & $0.498^{\star *}$ & 0.011 & $\times$ \\
\cline { 2 - 6 } & O-WB & 0.163 & $0.539^{* *}$ & 0.000 & $\times$ \\
\hline \multirow{2}{*}{ Q6 } & O-R & 0.198 & $0.290^{\star *}$ & 0.000 & $\times$ \\
\cline { 2 - 6 } & O-WB & 0.363 & $0.319^{* *}$ & 0.000 & $\times$ \\
\hline
\end{tabular}

Note: " $\mathrm{n}$ " means the sample size; $\mathrm{O}$ means $\mathrm{O}-\mathrm{Scheme}$, and $\mathrm{R}$ is $\mathrm{R}$-Scheme, WB is WB-Scheme; ${ }^{*}$ Means when the confidence level is 0.010 , the difference is significant (two-tails). " $x$ " means none of the two alternatives ( $\mathrm{R}$ and WB color schemes) could replace of original color scheme. 
Performance of color schemes in landscape preference evaluation

Q1, "Do you think the urban landscape reflected in the photo is beautiful?" referred to a respondent's aesthetic judgment. The mean values of Q1 under the O-, R- and WB-Schemes were 3.146, 3.176 and 3.043 , respectively. The mean difference between $\mathrm{O}$ - and R-Schemes was -0.030 (The maximum mean difference occurred on the judgment of $S 5$, with a value of -0.360 , and the minimum mean difference was on $S 4,-0.010$, Figure 4 ), while it was 0.103 between $\mathrm{O}$ - and WB-Schemes (The maximum mean difference was on $S 3,0.320$, and the minimum difference was on S5, -0.010 , Figure 4 ). Both O-R and O-WB correlations were significant $(\mathrm{p}<0.050$, two-tailed). There existed a significant difference ( $\mathrm{p}<0.050$, two-tailed) between the O- and WB-Schemes, while no significant difference ( $\mathrm{p}<0.050$, two-tailed) could be detected between $\mathrm{O}$ - and R-Schemes. This meant that the R-Scheme, but not the WB-Scheme, could replace the O-Scheme, when Q1was considered.

The mean values of the respondents' judgments to Q2, "Are you willing to live in the city reflected in the photo?" were $3.077,3.144$ and 2.995 under the O-, R- and WBSchemes, respectively. The mean difference between $\mathrm{O}$ - and R-Schemes was -0.067 (The maximum mean difference was on $S 5$, with a value of -0.450 , and the minimum mean difference was on S6, 0.000, Figure 4, and 0.082 between $\mathrm{O}-$ and WB-Schemes (The maximum difference was on
S6, 0.350, and the minimum difference was on S3, 0.050, Figure 4). A significant correlation ( $\mathrm{p}<0.050$, two-tailed) existed both between O- and R-Schemes, and O- and WBSchemes. The differences between O- and R-Schemes as well as O- and WB-Schemes are significant ( $\mathrm{p}<0.050$, twotailed). Neither the R- nor the WB-Schemes could replace the O-Scheme, if Q2 was the test question.

Performance of color schemes on judgments of naturalness, characteristics and color matching

Both Q3, "What is the approximate proportion of the natural landscape elements (Greensward, trees, hill body, water surface) to the whole landscape in the photo?", and Q4, "How do you feel about the naturalness of the urban landscape reflected in the photo?" were designed to detect respondents' judgement of and perception of the naturalness contained in the six considered scenes. Among them, Q3 reflected a participant's ability on identifying natural elements in the photos, which was a nominal variable, and Q4 reflected a participant's cognition about a photo's naturalness, which was an ordinal variable.

The mean values of Q3 under the O-, R- and WBSchemes were 2.615, 2.747 and 2.475 , respectively. The mean difference between the O- and R-Schemes was -0.132 (The maximum mean difference was on S5, -0.360 , and the minimum were on S1, 0.060 and S2, -0.060 , Figure 4), while the mean difference between the O- and WB-Schemes was 0.141 (The maximum mean difference

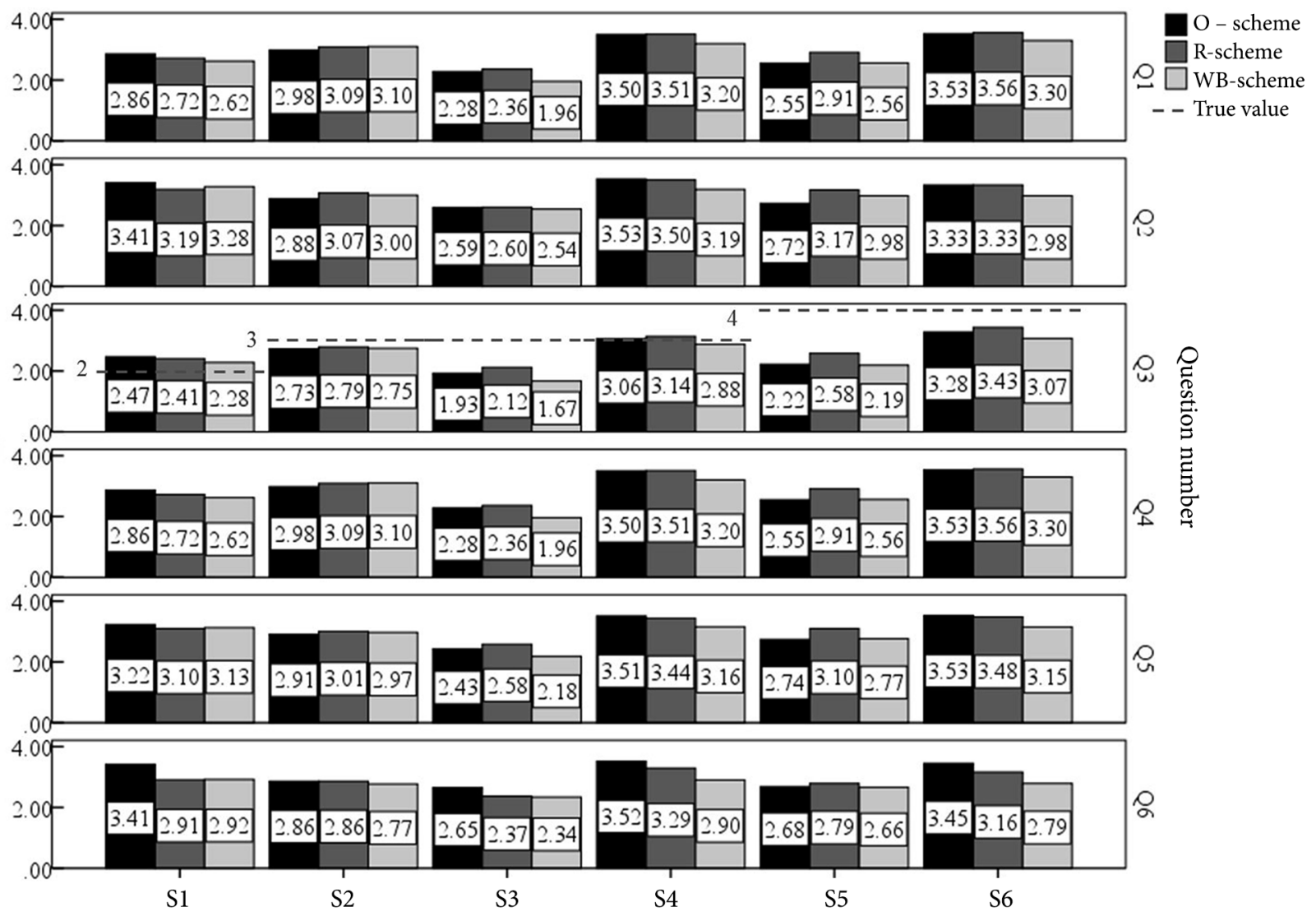

Figure 4. The mean value of different scenes and different questions under three-color schemes 
was on $S 3,0.260$, and the minimum was on $S 2,-0.020$, Figure 4). The O-WB and O-R correlations were significant $(\mathrm{p}<0.050$, two-tailed), while the O-WB and O-R differences were also significant ( $\mathrm{p}<0.050$, two-tailed). The actual naturalness of each scene, as indicated by the proportion of natural elements in each scene photo (Figure 1), could be classified using the same category in Q3 (Table 2), e.g. 1 for $<20 \%, 2$ for $20-40 \%, 3$ for $40-60 \%, 4$ for $60-80 \%$ and 5 for $>80 \%$. The actual category and the respondents' judgment of the nature proportion of each scene photo were illustrated in Figure 4. Overall, except S2 and $\mathrm{S} 4$, the respondents' judgment deviated seriously from the true level of naturalness in the other four test scenes. In terms of the performance of the three-color schemes, the respondents' judgment of naturalness of S2, S3, S5 and S6 was much closer to reality under the R-Scheme conditions than that under the other 2 color schemes. The WB-Scheme and O-Scheme had a better performance in S1 and S4 separately.

No matter how great the gap of the photo's naturalness between participants' judgment and actual situation was, the analysis showed that the participants' judgment of the photo's naturalness (Q4) was affected significantly by the judgment of the natural element proportion (Q3), as demonstrated by the strong correlation between Q3 and Q4 ( $\mathrm{r}=0.730, \mathrm{p}<0.01)$. The mean values of Q4 under the O-, R- and WB-Schemes were 2.949, 3.025 and 2.790 , respectively. The O-R mean difference was -0.076 (The maximum mean difference happened on S5, -0.360 , and the minimum was on $S 4,-0.010$, Figure 4 ), while the $\mathrm{O}-\mathrm{WB}$ mean difference was 0.159 (The maximum mean difference happened on S3, 0.320, and the minimum was on S5, -0.010 , Figure 4). There was a significant correlation ( $\mathrm{p}<0.050$, two-tailed) between O- and WB-Schemes, as well as $\mathrm{O}$ - and R-Schemes. The differences among them were also significant ( $\mathrm{p}<0.050$, two-tailed). In general, neither the R- nor the WB-Scheme could replace the OScheme, when Q3 and Q4 were considered.

With Q5, "How do you think the characteristic of the urban landscape reflected in the photo?", the landscape characteristics were taken into consideration. The mean value of the respondents' judgment on landscape characteristics under the O-, R- and WB-Schemes were 3.057, 3.118 and 2.895 , respectively. The mean difference between the O- and R-Schemes was 0.061 (The maximum mean difference was on $\mathrm{S} 5,-0.360$, and the minimum was on S6, 0.050, Figure 4), while that between O-and WBSchemes was 0.163 (The maximum mean difference was on S6, 0.380 , and the minimum was on S5, -0.030 , Figure 4). The correlation between O- and WB-Schemes, as well as between $\mathrm{O}$ - and R-Schemes, were both significant $(\mathrm{p}<0.050$, two-tailed). The difference between the $\mathrm{O}$ - and WB-Schemes was significant ( $<<0.050$, two-tailed), while a significance difference was seen between the $\mathrm{O}$ - and RSchemes, which was between 0.010 and 0.050 (Table 4). Therefore, it is not recommended to use the R- or WBScheme to replace the O-Scheme when the question is about landscape characteristics.
Respondents showed different color preference matching under different color schemes, with mean values of 3.095, 2.897 and 2.732 under the O-, R- and WB-Schemes, respectively. The O-R mean difference was 0.198 , while the O-WB mean difference was 0.363 . While the correlation between O-Scheme and WB-Scheme, and O-Scheme and R-Scheme were significant ( $\mathrm{p}<0.050$, two-tailed), the differences between them were also significant $(\mathrm{p}<0.050$, two-tailed). The two substitute schemes cannot replace the O-Scheme.

\section{Influence mechanisms of color schemes}

A further partial correlation analysis, in which Q1 and Q2 were treated as dependent variables and Q4, Q5, Q6 as independent variables, was carried out to compare the contribution of the impact factors to landscape preference. This sheds light on the influence mechanism of the color scheme preference. The results were shown in Table 5.

Table 5. Partial correlation coefficients of Q4, Q5, Q6 for Q1, Q2 under three-color schemes

\begin{tabular}{|l|c|c|c|c|c|c|}
\hline \multirow{2}{*}{} & \multicolumn{3}{|c|}{ Q1 } & \multicolumn{3}{c|}{ Q2 } \\
\cline { 2 - 7 } & $\mathrm{O}$ & $\mathrm{R}$ & $\mathrm{WB}$ & $\mathrm{O}$ & $\mathrm{R}$ & $\mathrm{WB}$ \\
\hline Q4 & 0.217 & 0.273 & 0.165 & 0.173 & 0.230 & 0.138 \\
\hline Sig. & 0.000 & 0.000 & 0.000 & 0.000 & 0.000 & 0.000 \\
\hline Q5 & 0.307 & 0.318 & 0.342 & 0.276 & 0.321 & 0.350 \\
\hline Sig. & 0.000 & 0.000 & 0.000 & 0.000 & 0.000 & 0.000 \\
\hline Q6 & 0.412 & 0.384 & 0.306 & 0.400 & 0.352 & 0.289 \\
\hline Sig. & 0.000 & 0.000 & 0.000 & 0.000 & 0.000 & 0.000 \\
\hline
\end{tabular}

Overall, landscape preference (Q1 and Q2) was subjected to three factors considered in this study: naturalness (Q4), landscape characteristic (Q5) and color matching (Q6), but the contribution rate of landscape preference was significantly different and was affected by color schemes used in test photos.

As shown in Table 5, under the O-Scheme, scene color matching (Q6) was the most influential factor in landscape preference among the three factors in consideration. Its contribution was approximately two times that of the weakest impact factor of naturalness (Q3). Therefore, under the O-Scheme, the preference for color matching of the scene to a large extent determined the landscape preference of the scene. For the R-Scheme, the scene color matching (Q6) was still the most important factor, but its importance was significantly reduced, along with a significantly increased contribution of the other two influence factors, particularly naturalness. Under the WB-Scheme, the influence importance of the three factors showed a completely different pattern. The most important influence factor was the landscape characteristic (Q5), where its contribution rate was more than two times that of the weakest impact factor naturalness (Q4). The factor color matching (Q6) was the second most important factor affecting landscape preference. 


\subsection{Performance of color schemes under different scenes}

The score distribution for each scene was illustrated in Figure 5.

As shown in Figure 5, the score distribution for scenes 3, 4 and 6 under the R-Scheme showed a similar pattern as that under the O-Scheme, while the score distribution under the WB-Scheme showed a completely different pattern. For S1 and S2, the score distributions were similar under the R- and WB-Schemes, but it was obviously different to that of the O-Scheme. As for S5, the score distribution under the different color schemes showed differentiated patterns, while the difference between $\mathrm{O}$ - and WB-Schemes was not as obvious as that between $\mathrm{O}$ - and R-Schemes.

Under different scenes, the correlation, mean difference values and differences significance of the threecolor schemes were listed in Table 6. A non-parametric
Table 6. Correlation, mean different values and difference significance of three color schemes under each scene $(\mathrm{n}=204 \times 6 \times 5)$

\begin{tabular}{|c|l|c|c|c|c|}
\hline & \multicolumn{1}{|c|}{ Pair } & Mean diff. & Correlation & Diff. Sig. & Alter. Sch. \\
\hline \multirow{2}{*}{ S1 } & O-R & 0.25 & $0.439^{* *}$ & 0.000 & $\times$ \\
\cline { 2 - 6 } & O-WB & 0.22 & $0.480^{* *}$ & 0.000 & $\times$ \\
\hline \multirow{2}{*}{ S2 } & O-R & -0.13 & $0.272^{* *}$ & 0.000 & $\times$ \\
\cline { 2 - 6 } & O-WB & -0.07 & $0.381^{* *}$ & 0.013 & $\times$ \\
\hline \multirow{2}{*}{ S3 } & O-R & 0.01 & $0.307^{* *}$ & 0.495 & $\mathrm{R}$ \\
\cline { 2 - 6 } & O-WB & 0.19 & $0.322^{* *}$ & 0.000 & $\times$ \\
\hline \multirow{2}{*}{ S4 } & O-R & 0.06 & $0.460^{* *}$ & 0.039 & $\times$ \\
\cline { 2 - 6 } & O-WB & 0.41 & $0.455^{* *}$ & 0.000 & $\times$ \\
\hline \multirow{2}{*}{ S5 } & O-R & -0.32 & $0.305^{* *}$ & 0.000 & $\times$ \\
\cline { 2 - 6 } & O-WB & -0.11 & $0.399^{* *}$ & 0.000 & $\times$ \\
\hline \multirow{2}{*}{ S6 } & O-R & 0.08 & $0.450^{* *}$ & 0.009 & $\times$ \\
\cline { 2 - 6 } & O-WB & 0.41 & $0.492^{* *}$ & 0.000 & $\times$ \\
\hline
\end{tabular}

$\mathrm{S} 1$

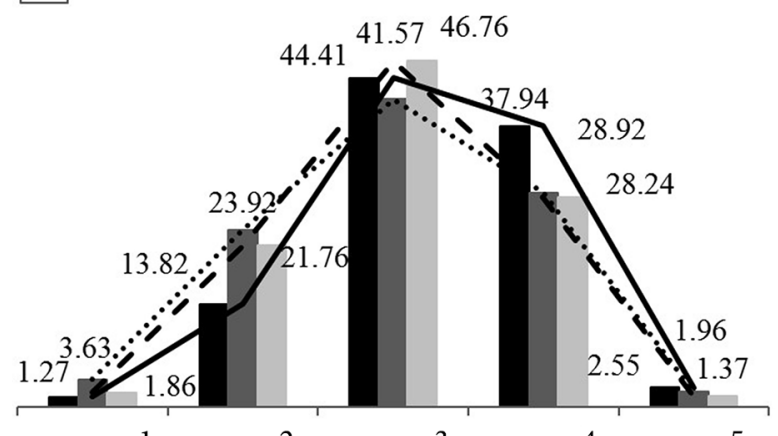

score $=1 \quad$ score $=2 \quad$ score $=3 \quad$ score $=4 \quad$ score $=5$

S3

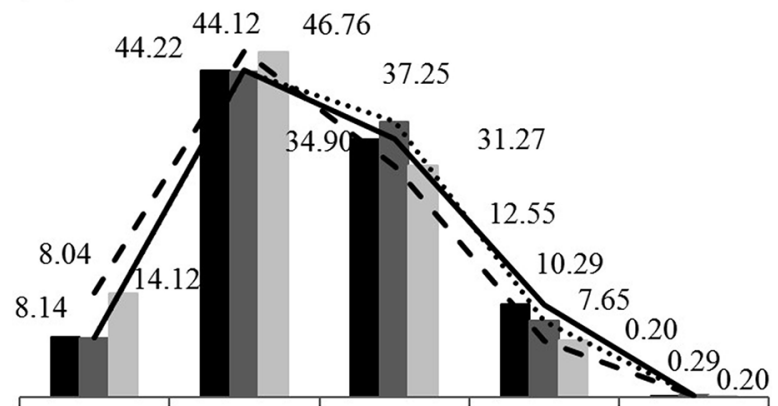

score $=1 \quad$ score $=2 \quad$ score $=3 \quad$ score $=4 \quad$ score $=5$ S5

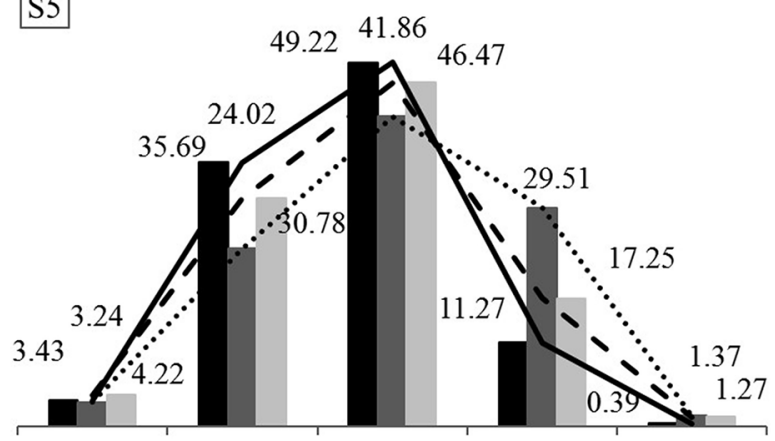

score $=1 \quad$ score $=2 \quad$ score $=3 \quad$ score $=4 \quad$ score $=5$

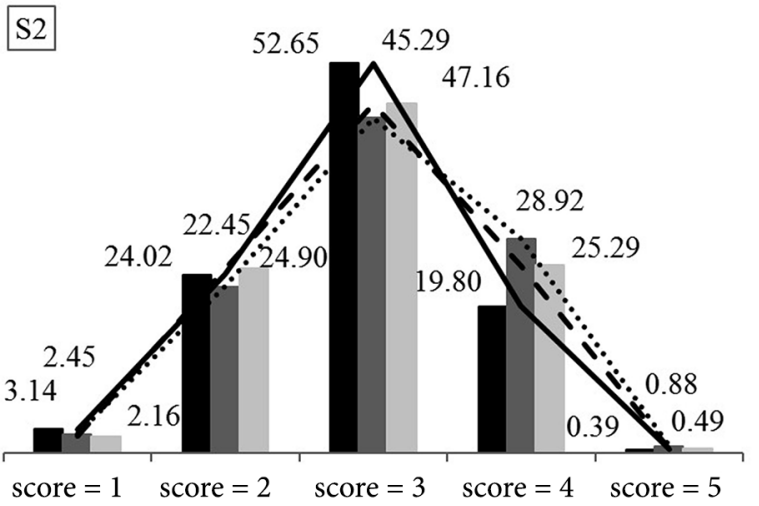

S4

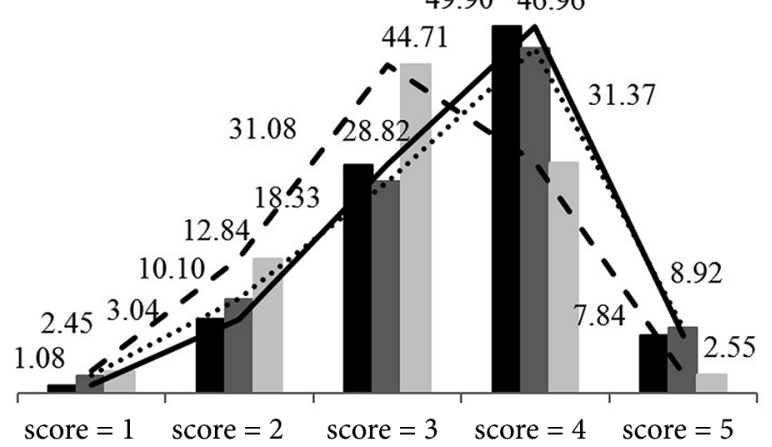

S6

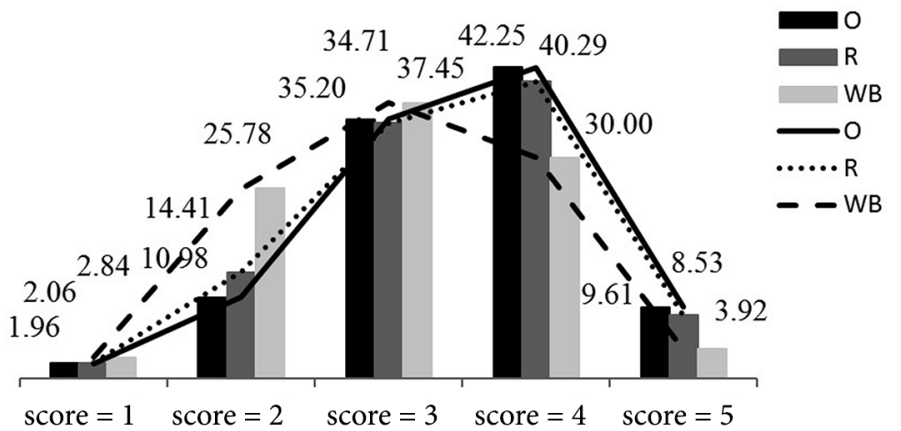

Figure 5. The score (percentage) proportion distribution for each scene over different color schemes 


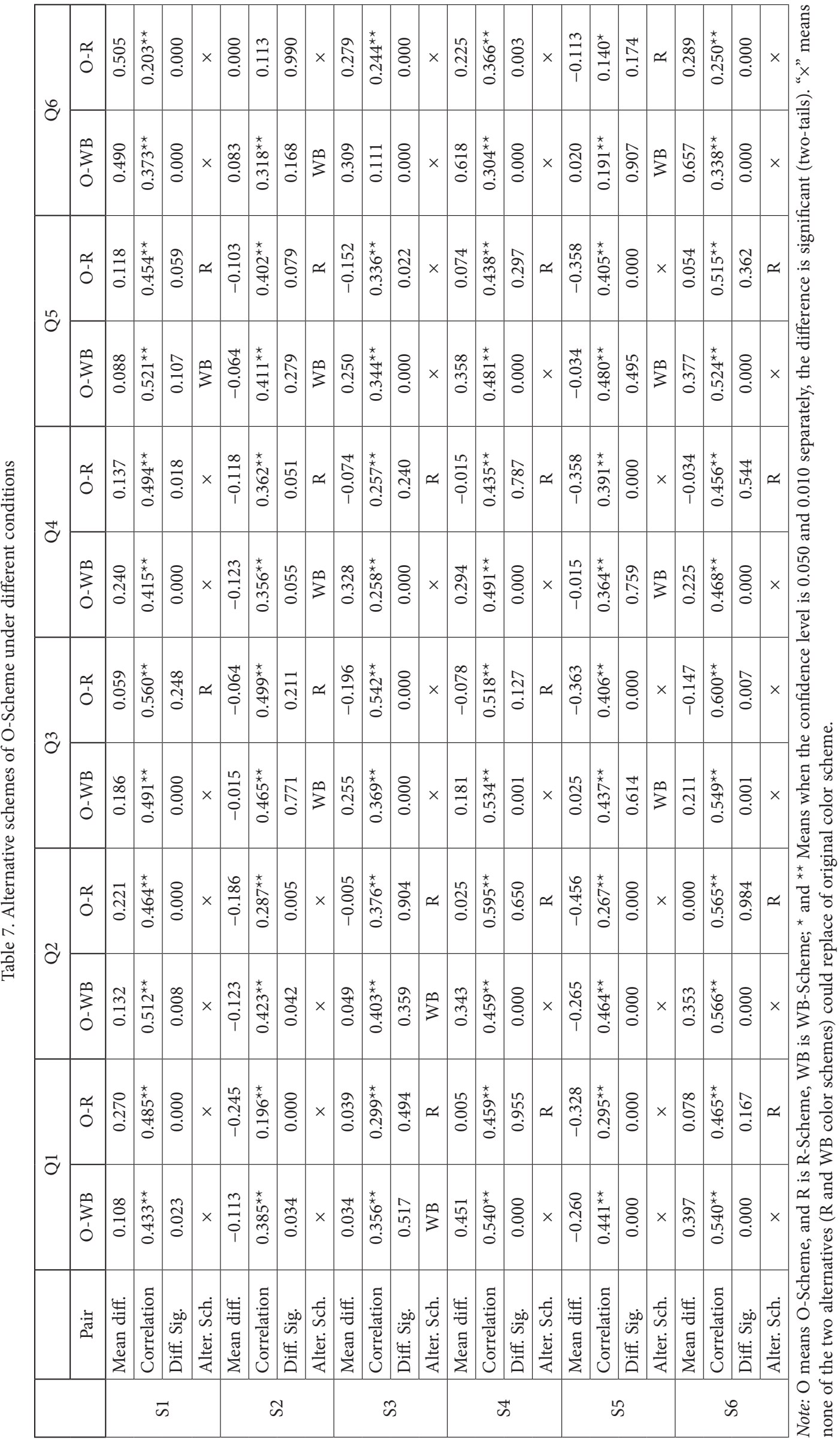


test showed that the correlation between the $\mathrm{O}$ - and $\mathrm{R}$ Schemes was significant ( $p<0.050$, two-tailed) for S3, S4 and $\mathrm{S} 6$, but no significant difference $(\mathrm{p}<0.050$, two-tailed) between them could be detected, which meant that the OScheme could be replaced by the R-Scheme in S3, S4 and S6. As for S1, S2 and S5, none of the two substitute color schemes could replace the O-Scheme. Therefore, overall, the R-Scheme outperformed the WB-Scheme, because in three $(\mathrm{S} 3, \mathrm{~S} 4, \mathrm{~S} 6)$ of the six scenes, the R-Scheme could replace the $\mathrm{O}-\mathrm{Scheme}$, and there were no conditions in which the WB-Scheme could replace the O-Scheme.

\subsection{Alternative color scheme(s)}

To distinguish these effects under different research contexts and different scenarios, Table 7 summarizes the performance of the three-color schemes under different conditions and the potential O-Scheme alternative color scheme.

Among the 36 combinations, there were 14 combinations where the O-Scheme was the only option, because the R- or WB-Schemes would lead to a significant difference in the test results. In 11 combinations, only the RScheme could completely replace the O-Scheme and will not had a significant impact on the test results. For three combinations only could the WB-Scheme completely replace the O-Scheme. For the final eight combinations, both the R- and WB-Schemes could replace the O-Scheme. To use the R- or WB-Scheme as an alternative color scheme to the $\mathrm{O}$-Scheme, one requires a corresponding selection according to the purpose of the study and the scene used in the test. Totally speaking, there were 18 combinations where the R-Scheme could replace the O-Scheme, which accounted for $50 \%$ of the total combinations. There were 11 combinations where the WB-Scheme could replace the O-Scheme, which accounted for $31 \%$; and finally, there were only 14 combinations where the O-Scheme could not be replaced by any of the alternatives, which accounted for $39 \%$. The general conclusion therefore was that the test results of the R-Scheme photos were closer to the O-Scheme than of the WB-Scheme.

\section{Discussions}

To better understand the role that different color schemes play on landscape preference, an approach was developed to transform an original color photo into a rendered photo. It was assumed that the rendered photo not only reflects scenes more objectively, compared with a whiteblack photo, but also avoids influencing factors such as weather and clouds in the original photo, which were normally caused by photo acquisition and could thus potentially influence the results of a landscape preference test. Meanwhile, the developed technique of photo color rendering avoids the disadvantage that the tone of the original photos is too delicate and complicated and not easy to control, through uniformly coloring the same type of landscape elements. Furthermore, by strengthening the chromatic aberration of different types of landscape elements, this technique ensured that the deviation in the test results caused by photo color schemes could be maintained in a controllable range. A comparison test of landscape preference was carried out using photos with different photo color schemes, i.e. original, rendered and white-black color schemes, as stimulus.

The results showed that, firstly, the photo color scheme in general and particularly white-black scheme would significantly affect the results of landscape preference test, and compared with white-black, the color in any conditions could increase a participant's preference for a given landscape. In comparison with the WB-Scheme, the variation ranges of the mean value of landscape preference under the $\mathrm{R}$ - or $\mathrm{O}$-Schemes could approximately reach a level of $5.6 \%$ in this study. Thus, one must be very careful when applying alternative color schemes in landscape preference study. Especially when using the WB-Scheme, as it cannot replace the $\mathrm{O}$-Scheme in most conditions. However, when referring to landscape characteristics, it turned out to be a suitable alternative color scheme. The R-Scheme showed excellent performance in general, and in the test, both under different research questions and test scenes. The results showed that the R-Scheme can replace the O-Scheme in almost $50 \%$ of the test scenarios and research questions, and does not lead to significant differences in the test results. In comparison, the WBScheme can replace the O-Scheme in only $31 \%$ of those conditions. Furthermore, with an increase in the proportion of natural elements in the photo ( $\mathrm{S} 1$ to $\mathrm{S6}$ ), the performance of R-Scheme seemed to get closer to that of the $\mathrm{O}$-Scheme. But the association between the two, that is, the correlation between photo naturalness and the substitution between $\mathrm{O}$-Scheme and R-Scheme, needed to be confirmed by more photo tests, rather than the six groups of photos tested in this study.

Secondly, it was worth noting that the color scheme played a decisive role in a respondent's judgment of some important landscape attributes (Kalivoda, Vojar, Skrivanova, \& Zahradnik, 2014), such as naturalness, landscape characteristic, color matching, which might strongly influence the landscape preference, as demonstrated in previous studies (Ode, Fry, Tveit, Messager, \& Miller, 2009; Mahdieh \& Mustafa Kamal, 2014). The results showed that both WB- and R-Schemes can significantly influence a respondent's judgment of the proportion of natural elements in a test photo $(\mathrm{Q} 3)$, perceived naturalness (Q4), satisfaction of color matching (Q6) and landscape characteristics (Q5). Furthermore, it was worth noting that a photo color scheme exerted its influence on landscape preference by changing the contribution rate of the above-mentioned landscape attributes to the total landscape preference. Compared with the O-Scheme, the R-Scheme would lead to a significant increase in the contribution of naturalness, although this was at the expense of a decline in color matching. The WB-Scheme could highlight the contribution of a landscape's characteristics, but at the expense of naturalness and color matching. 
Finally, when estimating the proportion of natural elements in a photo, there were significant differences between the estimated value and the actual value of the scenes. It was worth noting that if the natural landscape elements were centralized and located in the center of view field, it will attract the attention of the respondents and enlarge their subjective feelings, and then lead to an overestimation of the proportion of natural elements. Otherwise (e.g. the landscape elements were scattered and located at the edges of view field), the estimation of landscape elements proportion will shrink. However, it seemed that the layout of either the R- or WB-Scheme could discourage any impact of naturalness cognition.

This research attempted to figure out the differences and consensus among three common used color schemes along with the study of human being's landscape preference for visual stimulation. Nevertheless, many critical issues need to be addressed in future research. For instance, how to connect behavioural research on landscape preference with the emerging field of neuraesthetics. As researches on landscape preference are mainly depend on respondents' response, which is the foundation of photo stimuli test.

\section{Conclusions}

Given that landscape photos are the most commonly used stimuli in landscape preference studies, in-depth study of the influence of different color schemes on landscape preference test results hadn't yet been widely conducted, due to the difficulties and complexity in quantifying public cognition reaction of landscape elements' colors. Thus, standardized color scheme is still open for discussion.

In conclusion, the results in this study revealed the importance of photo color and particularly gave a specific way on how to determine the medium's color in a particular landscape preference test. As different color treatments will affect the results of landscape preference test, one should make a clearly defined objective when draw up an alternative color scheme in landscape preference studies, especially when residents' put different weights on their particular preference toward their living scenarios (color, characteristics, naturalness et al.).

The approach may lead to a further discussion in landscape cognition research, for example, discussion on the demographic difference in landscape color cognition or discussion on a methodological standard for properly using color model in landscape preference test.

\section{Acknowledgments}

This work was supported by the National Key R\&D Program of China [grant number 2018YFC0704705 and 2016YFC0502903], and the National Natural Science Foundation of China [grant number 41371192].

\section{References}

Acar, C., Kurdoglu, B. C., Kurdoglu, O., \& Acar, H. (2006). Public preferences for visual quality and management in the Kackar Mountains National Park (Turkey). International Journal of Sustainable Development \& World Ecology, 13(6), 499-512. https://doi.org/10.1080/13504500609469699

Atik, M., Isikli, R. C., \& Ortacesme, V. (2016). Clusters of landscape characters as a way of communication in characterisation: A study from side, Turkey. Journal of Environmental Management, 182, 385-396.

https://doi.org/10.1016/j.jenvman.2016.07.076

Chesnokova, O., \& Purves, R. S. (2018). From image descriptions to perceived sounds and sources in landscape: Analyzing aural experience through text. Applied Geography, 93, 103-111. https://doi.org/10.1016/j.apgeog.2018.02.014

Deussen, O. (2003). A framework for geometry generation and rendering of plants with applications in landscape architecture. Landscape and Urban Planning, 64(1-2), 105-113. https://doi.org/10.1016/S0169-2046(02)00216-5

Dupont, L., Antrop, M., \& Van Eetvelde, V. (2015). Does landscape related expertise influence the visual perception of landscape photographs? Implications for participatory landscape planning and management. Landscape and Urban Planning, 141, 68-77. https://doi.org/10.1016/j.landurbplan.2015.05.003

Fechner, G. T. (1876). Vorschule der aesthetik. Germany: Breitkopf \& Härtel.

Garcia, L., Hernández, J., \& Ayuga, F. (2003). Analysis of the exterior colour of agroindustrial buildings: a computer aided approach to landscape integration. Journal of Environmental Management, 69(1), 93-104. https://doi.org/10.1016/S0301-4797(03)00121-X

Gong, R., Wang, Q., Hai, Y., \& Shao, X. (2017). Investigation on factors to influence color emotion and color preference responses. Optik - International Journal for Light and Electron Optics, 136, 71-78.

Hayden, L., Cadenasso, M. L., Haver, D., \& Oki, L. R. (2015). Residential landscape aesthetics and water conservation best management practices: Homeowner perceptions and preferences. Landscape and Urban Planning, 144, 1-9.

https://doi.org/10.1016/j.landurbplan.2015.08.003

Hu, H., Ge, Y., \& Hou, D. (2014). Using web crawler technology for geo-events analysis: a case study of the Huangyan Island incident. Sustainability, 6(4), 1896-1912.

https://doi.org/10.3390/su6041896

Kalivoda, O., Vojar, J., Skrivanova, Z., \& Zahradnik, D. (2014). Consensus in landscape preference judgments: the effects of landscape visual aesthetic quality and respondents' characteristics. Journal of Environmental Management, 137, 36-44. https://doi.org/10.1016/j.jenvman.2014.02.009

López-Martínez, F. (2017). Visual landscape preferences in Mediterranean areas and their socio-demographic influences. Ecological Engineering, 104, 205-215.

https://doi.org/10.1016/j.ecoleng.2017.04.036

Lange, E., Hehl-Lange, S., \& Brewer, M. J. (2008). Scenario-visualization for the assessment of perceived green space qualities at the urban-rural fringe. Journal of Environmental Management, 89(3), 245-256. https://doi.org/10.1016/j.jenvman.2007.01.061

Lee, K. C., \& Son, Y. H. (2017). Exploring landscape perceptions of Bukhansan National Park according to the degree of visitors' experience. Sustainability, 9(8), 1306. https://doi.org/10.3390/su9081306 
Lengen, C. (2015). The effects of colours, shapes and boundaries of landscapes on perception, emotion and mentalising processes promoting health and well-being. Health \& Place, 35, 166-177. https://doi.org/10.1016/j.healthplace.2015.05.016

Lindquist, M., Lange, E., \& Kang, J. (2016). From 3D landscape visualization to environmental simulation: The contribution of sound to the perception of virtual environments. Landscape and Urban Planning, 148, 216-231.

https://doi.org/10.1016/j.landurbplan.2015.12.017

Mahdieh, P., \& Mustafa Kamal, M. S. (2014). Effect of predictors of visual preference as characteristics of urban natural landscapes in increasing perceived restorative potential. Urban Forestry \& Urban Greening, 13(1), 145-151. https://doi.org/10.1016/j.ufug.2013.08.005

Nardecchia, F., Barbalace, M., Bisegna, F., Burattini, C., Gugliermetti, F., Vollaro, A., \& Golasi, I. (2015). A method to evaluate the stimulation of a real world field of view by means of a spectroradiometric analysis. Sustainability, 7, 14964-14981.

Natori, Y., \& Chenoweth, R. (2008). Differences in rural landscape perceptions and preferences between farmers and naturalists. Journal of Environmental Psychology, 28(3), 250-267. https://doi.org/10.1016/j.jenvp.2008.02.002

Nejati, A., Rodiek, S., \& Shepley, M. (2016). Using visual simulation to evaluate restorative qualities of access to nature in hospital staff break areas. Landscape and Urban Planning, 148, 132-138. https://doi.org/10.1016/j.landurbplan.2015.12.012

Ode, A., Fry, G., Tveit, M. S., Messager, P., \& Miller, D. (2009). Indicators of perceived naturalness as drivers of landscape preference. Journal of Environmental Management, 90(1), 375-383. https://doi.org/10.1016/j.jenvman.2007.10.013

Orenstein, D. E., Zimroni, H., \& Eizenberg, E. (2015). The immersive visualization theater: A new tool for ecosystem assessment and landscape planning. Computers, Environment and Urban Systems, 54, 347-355.

https://doi.org/10.1016/j.compenvurbsys.2015.10.004

Palmer, S. E., Schloss, K. B., \& Sammartino, J. (2013). Visual aesthetics and human preference. Annual Review Psychology, 64, 77-107.

https://doi.org/10.1146/annurev-psych-120710-100504

Polat, A. T., \& Akay, A. (2015). Relationships between the visual preferences of urban recreation area users and various landscape design elements. Urban Forestry \& Urban Greening, 14(3), 573-582. https://doi.org/10.1016/j.ufug.2015.05.009

Schloss, K. B., \& Palmer, S. E. (2017). An ecological framework for temporal and individual differences in color preferences. Vision Research, 141, 95-108. https://doi.org/10.1016/j.visres.2017.01.010

Soini, K., Vaarala, H., \& Pouta, E. (2012). Residents' sense of place and landscape perceptions at the rural-urban interface.
Landscape and Urban Planning, 104(1), 124-134. https://doi.org/10.1016/j.landurbplan.2011.10.002

Sowińska-Świerkosz, B. (2016). Index of Landscape Disharmony (ILDH) as a new tool combining the aesthetic and ecological approach to landscape assessment. Ecological Indicators, 70, 166-180. https://doi.org/10.1016/j.ecolind.2016.05.038

Stamps, A. E. (1990). Use of photographs to simulate environments: A meta-analysis. Perceptual and Motor Skills, 71(3), 907-913. https://doi.org/10.2466/pms.1990.71.3.907

Surová, D., \& Pinto-Correia, T. (2016). A landscape menu to please them all: Relating users' preferences to land cover classes in the Mediterranean region of Alentejo, Southern Portugal. Land Use Policy, 54, 355-365. https://doi.org/10.1016/j.landusepol.2016.02.026

Svobodova, K., Sklenicka, P., Molnarova, K., \& Vojar, J. (2014). Does the composition of landscape photographs affect visual preferences? The rule of the Golden Section and the position of the horizon. Journal of Environmental Psychology, 38, 143152. https://doi.org/10.1016/j.jenvp.2014.01.005

Tieskens, K. F., Van Zanten, B. T., Schulp, C. J. E., \& Verburg, P. H. (2018). Aesthetic appreciation of the cultural landscape through social media: An analysis of revealed preference in the Dutch river landscape. Landscape and Urban Planning, 177, 128-137. https://doi.org/10.1016/j.landurbplan.2018.05.002

Verbrugge, L., \& van Den Born, R. (2018). The role of place attachment in public perceptions of a re-landscaping intervention in the river Waal (The Netherlands). Landscape and Urban Planning, 177, 241-250. https://doi.org/10.1016/j.landurbplan.2018.05.011

Wang, R., \& Zhao, J. (2017). Demographic groups' differences in visual preference for vegetated landscapes in urban green space. Sustainable Cities and Society, 28, 350-357. https://doi.org/10.1016/j.scs.2016.10.010

Wang, R., Zhao, J., \& Liu, Z. (2016). Consensus in visual preferences: The effects of aesthetic quality and landscape types. Urban Forestry \& Urban Greening, 20, 210-217. https://doi.org/10.1016/j.ufug.2016.09.005

Yamashita, S. (2002). Perception and evaluation of water in landscape: use of Photo-Projective Method to compare child and adult residents' perceptions of a Japanese river environment. Landscape and Urban Planning, 62(1), 3-17. https://doi.org/10.1016/S0169-2046(02)00093-2

Zhang, H., Chen, B., Sun, Z., \& Bao, Z. (2013). Landscape perception and recreation needs in urban green space in Fuyang, Hangzhou, China. Urban Forestry \& Urban Greening, 12(1), 44-52. https://doi.org/10.1016/j.ufug.2012.11.001 